\title{
Gestational Rheumatology
}

\author{
Hanan Al-Osaimi and Areej Althubiti
}

\subsection{Introduction}

There are changes that occur in the maternal organ systems due to increased demands of pregnancy. Most of the rheumatic disorders occur in the reproductive age group. The hormonal changes that occur during pregnancy may mimic the signs and symptoms of rheumatic disorders thereby making the diagnosis difficult. Rheumatological disorders need to be diagnosed and treated at least 6 months before the onset of pregnancy; otherwise they may have considerable effect on the prognosis of the disease. This is particularly evident in cases of SLE and antiphospholipid antibody syndrome. Therefore, pregnancy is a crucial issue that needs to be clearly addressed in details in all female patients in the reproductive age group having some of the rheumatological disorders.

There are two concerns in these patients. The first one is the effect of the disease activity on pregnancy, and the second is the influence of pregnancy on the disease. That explains why pregnancy should be planned carefully at least 6 months of remission before attempting pregnancy. This is supported with close follow-up for the disease activity during pregnancy. Therefore,

H. Al-Osaimi $(\bowtie)$

King Fahad Armed Forces Hospital, Jeddah, Saudi Arabia

A. Althubiti

Saudi Commission for Health Specialties,

Riyadh, Saudi Arabia managing pregnant patients with rheumatic disease can be very challenging. The simple explanation is the combination of aggravation of disease by pregnancy, the aggravation of pregnancy by disease, and the use of special medications in pregnancy. A successful pregnancy requires achievement of multiple biological steps from "conception, embryogenesis, placental and fetal development, maternal-fetal communication to labor and delivery" [1].

\subsection{Objectives}

By the end of this chapter, you should be able to:

1. To discuss the physiology of pregnancy.

2. To discuss systemic lupus erythematosus flare manifestations and management during pregnancy.

3. To diagnose and manage antiphospholipid syndrome during pregnancy.

4. To discuss neonatal lupus erythematosus pathophysiology and management.

5. Review management of other common rheumatologic diseases during pregnancy.

\subsection{Physiology of Pregnancy}

There are added burden by the mother, the fetus, and the placenta during pregnancy. All of these should be met by the mother's organ systems. 
Thus, there are certain cardiovascular, hematological, immunological, endocrinal, and metabolic changes that happen in the mother in normal pregnancy.

\subsubsection{Changes in Cardiovascular System}

The most important physiological changes that happen in pregnancy are the increase in cardiac output and retention of sodium and water. These changes result in significant increase in blood volume and reduction in systemic vascular resistance and blood pressure. Such changes start as early as fourth week of pregnancy, reaching their highest level during the second trimester, and then remain relatively constant until delivery. As the increase in the red cell volume is proportionately much less than the increase in plasma volume, there is hemodilution (physiological anemia) by the end of second trimester [2].

The increased level of plasma erythropoietin is responsible for balanced increase in the red cell mass. The physiological anemia that happens in pregnancy reduces the cardiac work load and helps for enhanced placental perfusion by decreasing the blood viscosity. It also decreases the risk of thrombosis in uteroplacental circulation. The increased blood volume also defends against the usual blood loss in the peripartum period.

Cardiac output increases by $30-50 \%$ during normal pregnancy. This is as a result of increase in the preload owing to rise in blood volume, decrease in afterload due to decrease in systemic vascular resistance, and increase in the maternal heart rate. The cardiac output and systemic vascular resistance steadily return to non-pregnant levels over a period of 3 months postpartum [3].

\subsubsection{Hematological Changes}

The total white cell count is increased up to $40 \%$, and the platelet count gradually declines till the term, while they do not fall below $100,000 / \mathrm{cu}$ $\mathrm{mm}$. This is expected as a result of dilutional effect, increased destruction, and turnover [4].

\subsubsection{Changes in Coagulation System}

Pregnancy is linked with changes in several coagulation factors that result in a $20 \%$ reduction of prothrombin and the partial thromboplastin times creating a hypercoagulable state. This acts as a double-edged sword, both for protection (e.g., hemostasis contributing to reduced blood loss at delivery) and increased risk (e.g., thromboembolic phenomenon). Venous thrombosis in pregnancy happens in approximately 0.7 per 1000 women and is three- to fourfold higher in the puerperium than during pregnancy. The risk is amplified in women with underlying inherited thrombophilia (e.g., factor V Leiden or the prothrombin gene mutation) [5].

\subsubsection{Changes in the Maternal Immune System}

The local modification of the maternal immune system is accountable for the successful coexistence between the mother and the fetus/placenta expressing both maternal (self) and paternal antigens. The cell-mediated adaptive immune responses are reduced, bypassed, or even eliminated. However, the antibody-mediated immunity is reformed, while the natural immunity (innate immunity) remains intact which continues to offer the host defense against infection. During insemination, the transforming growth factor $\beta 1$ (TGF- $\beta 1$ ), found in the seminal fluid, excites the production of granulocytemacrophage colony-stimulating factor (GM-CSF) and enrolment of inflammatory cell infiltrates in the uterus [6].

During implantation of the fertilized ovum, the majority of the lymphocytes infiltrating the decidua are typical uterine natural killer (NK) cells which are CD56++, CD16-, and CD3- and express various receptors. Uterine decidua and the fetoplacental unit produce large number of cytokines which contribute to shift of the immune response from $\mathrm{T}$ helper 1 (Th1) to $\mathrm{T}$ helper 2 (Th2) response. While there are many specific mechanisms for immunological protection 
against the fetus, the most essential one is altered HLA expression [7].

\subsubsection{Changes in the Endocrine Glands}

Maternal changes in pregnancy involve the hypothalamus, pituitary, parathyroid, adrenal glands, and ovaries to adapt the needs of the fetalplacental-maternal unit. The hypothalamus still controls much of the endocrine system through hypothalamic-pituitary axis, directly affecting the function of the abovementioned endocrine organs.

(a) Hypothalamus: These hormones released from hypothalamus are available in high concentrations in portal circulation where they are biologically active. The circulating concentrations of many of these hormones are also raised in pregnancy due to placental production of identical or variant hormones [8].

The most important changes are seen in the following hormones:

\section{Gonadotropin-releasing hormone} (GnRH) level increases during pregnancy. The main source is the placenta and exerts a main role in placental growth and function. Corticotropin-releasing hormone (CRH) from hypothalamus is engaged in stress response in pregnancy and delivery. It is also released by the placenta, chorionic trophoblasts, amnion, and decidual cells. The placental $\mathrm{CRH}$ do not stimulate adrenocorticotropic hormone (ACTH) secretion but helps in induction of labor. Besides $\mathrm{CRH}$ the gestational tissues also secrete urocortin which shares the same function as that of placental CRH. The urocortin-2 also controls the tone of vascular endothelium which also plays a major role in parturition [9].

(b) Pituitary Gland: Anterior lobe of pituitary gland expands threefold during gestation because of hypertrophy and hyperplasia of lactotrophs. It needs minimum 6 months after delivery to return to normal size. Follicle-stimulating hormone (FSH), lutein- izing hormone (LH), and thyroid-stimulating hormone (TSH) levels are decreased, while growth hormone $(\mathrm{GH}), \mathrm{ACTH}$, and prolactin (PRL) levels are increased mainly due to the synthesis by the placenta.

The serum PRL concentration increases due to increase estradiol during pregnancy, reaching the maximum at delivery to prepare the breast for lactation. The plasma sodium concentration drops by $5 \mathrm{meq} / \mathrm{L}$ due to resetting of osmoreceptors as a result of increased levels of human chorionic gonadotropin (HCG). Oxytocin level increases steadily during gestation and is involved in parturition and lactation. There is increase in thyroxin-binding globulin (TBG) but TSH (along with triiodothyronine (T3) and thyroxin (T4)) is in the normal range [10].

The renin-angiotensin-aldosterone system is stimulated during pregnancy due to reduction in peripheral vascular resistance and blood pressure, but there is a gradual decline in vascular responsiveness to angiotensin II. The aldosterone level increases by four- to sixfold, and the blood pressure usually reduces by $10 \mathrm{mmHg}$. Relaxin, a vasodilator factor produced by the placenta and aldosterone, is critical in sustaining sodium balance in the setting of peripheral vasodilatation. During pregnancy there is an increase in the levels of maternal and placental ACTH, cortisolbinding protein, atrial natriuretic peptide (ANP), plasma rennin activity (PRA), sex hormonebinding protein, and testosterone levels [11].

\subsection{Systemic Lupus Erythematosus}

\subsubsection{Introduction}

Systemic lupus erythematosus (SLE) is a chronic multisystem autoimmune disease occurring in young women in their childbearing age. It is one of the most common rheumatological conditions encountered in pregnancy with considerable influence on its outcome. It mainly affects the skin, joints, blood, kidney, and other organs. Pregnancy can have influence on the disease, and 
the disease also has considerable influence on pregnancy.

The annual incidence of SLE is 3 cases per 100,000 population out of which $90 \%$ belong to the female gender. Asians and African Americans found to have more severe disease with renal involvement. The thrombotic complications are seen in $10 \%$ of these cases [12]. SLE is a hypercoagulable state due to antiphospholipid antibodies and increase in certain procoagulants due to inflammation and platelet hyperfunction. This further leads to thrombogenesis by multiple-hit theory. The factors which increase thrombosis risk also encourage pregnancy loss in lupus.

\subsubsection{Influence of Pregnancy on SLE}

SLE patients experience different kinds of pregnancy related complications more than non-SLE women. One of the common pregnancy-related complications are pregnancy-induced hypertension (PIH); preeclampsia (blood pressure $\geq 140 / 90 \mathrm{mmHg}$ after 20 weeks of gestation and proteinuria $\geq 300 \mathrm{mg} / 24 \mathrm{hrs}$ ), eclampsia (preeclampsia plus seizures), HELLP syndrome (hemolysis, elevated liver enzymes, and low platelets), and gestational diabetes [13].

\subsubsection{Lupus Flares}

The risk of lupus flare is enlarged if the woman has had active lupus in the last 6 months of pregnancy. Therefore, quiescent disease at the onset of pregnancy offers optimum protection against the occurrence of flare during pregnancy [14]. Lupus may flare through any trimester of pregnancy or postpartum period. The flares are usually mild mainly involving the joints, skin, and blood. Some of the physiological changes of pregnancy can simulate the symptoms of the active disease such as palmar erythema, arthralgia, myalgia, and lower limb edema.

The laboratory data specific for lupus flare as compared to pregnancy data include rising titer of anti-double strand DNA antibodies, presence of red blood cell casts in the urine, positive direct
Coombs test, and presence of antiplatelet antibody with thrombocytopenia. Complement levels can be in natural range as complement levels increase during pregnancy due to estrogeninduced hepatic synthesis of complements. Hence, it is important to differentiate lupus flare from pregnancy-related complications and physiological changes of pregnancy [15].

Previous studies have suggested that several factors may increase the risk of preeclampsia in pregnancies complicated by SLE. These factors include preexisting hypertension, renal insufficiency, presence of APS, as well as active SLE [16]. The differentiating features of preeclampsia from lupus nephritis are mentioned in Table 17.1.

\subsubsection{Lupus Nephritis (LN)}

Lupus pregnancies with long-standing $\mathrm{LN}$ are at high risk of spontaneous abortions and increased perinatal and maternal mortality. However, the outcome of pregnancy in patients with stable $\mathrm{LN}$ at conception is relatively favorable. Remission in lupus nephritis has been defined as stable renal function, a serum creatinine within the normal range, urinary red cells below 5/high power field, proteinuria below $0.5 \mathrm{~g} / \mathrm{day}$, and ideally normal

Table 17.1 Broad guidelines to differentiate lupus nephrites from preeclampsia

\begin{tabular}{|c|c|c|}
\hline Parameter & $\begin{array}{l}\text { Active lupus } \\
\text { nephritis }\end{array}$ & Preeclampsia \\
\hline High BP & Present or absent & $\begin{array}{l}\text { Diastolic } \\
\mathrm{BP}>90 \mathrm{mmHg}\end{array}$ \\
\hline Proteinuria & $\begin{array}{l}\text { - }>500 \mathrm{mg} / 24 \mathrm{~h} \\
\text { if normal } \\
\text { baseline } \\
\text { Doubling if } \\
>500 \mathrm{mg} / 24 \mathrm{~h} \\
\text { at baseline. } \\
\text { Occur before } \\
\text { third trimester. }\end{array}$ & $\begin{array}{l}\text { - }>300 \mathrm{mg} / 24 \mathrm{~h} \\
\text { if normal } \\
\text { baseline } \\
\text { - Occur during } \\
\text { third trimester. }\end{array}$ \\
\hline Edema & Present/absent & Present/absent \\
\hline $\begin{array}{l}\text { Active } \\
\text { sediment }\end{array}$ & Present/absent & Absent \\
\hline Uric acid & Normal or elevated & Elevated \\
\hline $\mathrm{C} 3, \mathrm{C} 4$ & Low & Normal \\
\hline $\begin{array}{l}\text { Anti-ds } \\
\text { DNA abs }\end{array}$ & Rising & Absent \\
\hline
\end{tabular}


serum complement component $3\left(\mathrm{C}_{3}\right)$ levels for the last 12-18 months [17]. LN flare can be associated with other findings of active lupus such as serositis, arthritis, and high titers of anti-DNA antibodies. The proteinuria of preeclampsia decreases after delivery but not that of active lupus patient.

\subsubsection{Influence of SLE on Pregnancy}

SLE patients are as fertile as the overall female population [18]. Reduced fertility rate is seen in patients with active disease on high-dose steroids, patients with proven renal disease, and patients with moderate to severe renal failure. End-stage renal disease resulting from $\mathrm{LN}$ can lead to amenorrhea. However, amenorrhea in renal patients may also be because of ovarian failure from cyclophosphamide use or of autoimmune origin [19].

Lupus flares can occur at any time during pregnancy with potential adverse effects on the conception. Lupus flares happen more commonly throughout pregnancy and postpartum period more than in non-pregnant SLE patients. Increase in lupus activity is seen at least in $1 / 3$ cases in pregnancy. Therefore, for a better outcome of lupus pregnancy, it is important to control disease activity and to achieve clinical remission for at least 6 months before pregnancy [20].

Adverse live-birth outcome was significantly correlated with low pre-gestational serum albumin level, elevated gestational anti-dsDNA antibody, and diabetes mellitus. Spontaneous abortion was directly correlated with low levels of pre-gestational serum albumin, positive anticardiolipin IgA, anti- $\mathrm{B}_{2}$-glycoprotein IgM, and anti-La antibodies. The risk of obstetric complications and maternal mortality is high in patients with active LN associated with preexisting hypertension [21].

\subsubsection{Hypercoagulability in SLE}

Pregnancy itself is a hypercoagulable state with fetal demise, thrombosis, and preeclampsia being associated with factor $\mathrm{V}$ Leiden mutation, prothrombin gene mutation 20210A, and deficiencies of anti-thrombin III, protein $\mathrm{C}$, and protein $\mathrm{S}$
[22]. Pregnancy complications in SLE are rather common with maternal hypertensive complications occurring in 10-20\%, preterm births in $20 \%$, fetal growth restriction occurring in about $28 \%$, and an average drop in fetal growth weight to around $16 \%$. The increased stillbirth rate in SLE is fourfold greater than the general population [23]. Hence, SLE-specific thrombophilic factors are additive to the background of pregnancy-related hypercoagulability (multiple hits). Collectively, this encourages the occurrence of worse fetal outcomes in lupus.

Hypercoagulability in SLE is due to multiple factors (multiple-hit theory)

(a) Lupus-specific procoagulant factors-APLA (antiphospholipid antibodies).

(b) Other lupus-specific factors include antibodies to factor XII, prothrombin, and annexin V [24].

(c) Lupus nonspecific factors.

(d) Non-lupus-related procoagulant factors.

Chronic inflammation happening in SLE patients contributes to the occurrence of thrombosis. The factors responsible for this state can be summarized into:

1. Elevated or activated procoagulant factorsfactors 2, 7, 8, 9, and 10, VWF, and fibrinogen.

2. Reduced anticoagulant factors-protein C, S, antithrombin III.

3. Inhibition of fibrinolysis - PAI-1 elevation, hyperhomocysteinemia.

4. Elevated ESR, CRP, high-sensitivity CRP (HsCRP), complement activation, fibrinogen.

5. Increase in proinflammatory cytokines: IL-1, IL-6, tumor necrosis factor (TNF), and vascular endothelial growth factor (VEGF) [24].

\subsubsection{Platelet Activation}

The prothrombotic effects of antiphospholipid antibodies occur through different mechanisms. They include platelet activation, endothelial cell activation with resultant upregulation of adhesion molecules and production of thromboxane A2, and stimulation of monocytes to make tissue factor. 
Ultimately, all this will enhance clotting and vasoconstriction. Tissue factor activates the extrinsic coagulation system, while tissue plasminogen activator (tPA) activates fibrinolysis. Tissue factor pathway inhibitor activity is diminished in SLE, and this is correlated with elevated levels of tissue factor and subsequent hypercoagulability [25].

\subsubsection{Lupus Platelets}

Inflammatory process in SLE leads to release of tissue factor which further leads to platelet activation. The antiphospholipid antibodies bind to activated platelet membrane ultimately leading to hyperfunction of platelets similar to sticky platelet syndrome. Hyperfunction of platelets in SLE is one of the important factors in causation of thrombosis [26].

\subsubsection{Laboratory Workup}

In general, more than basic tests are needed to evaluate the full range of possibly disrupted clotting mechanisms. This involves testing for lupus-specific antiphospholipid antibodies and other hemostatic markers of coagulation. The lupus-specific antibodies include lupus anticoagulant, anticardiolipin antibodies, and anti- $\beta-2$ glycoprotein- 1 antibodies. These antiphospholipid antibodies are a heterogeneous group of antibodies identified by various laboratory techniques; each of them has some problems with standardization, specificity, interpretation, and quality control [27]. The target antigens for these different antibodies involve prothrombin and negatively charged phospholipids [28].

Apart from antiphospholipid antibodies, a coagulation risk laboratory profile also necessitates to be checked in lupus patients with thrombosis and fetal loss. Such profile includes testing for fibrinogen, factor VII, factor VIII, tPA, PAI-1, plasminogen activity, von Willebrand factor activity and antigen, protein $\mathrm{C}$ activity, protein $\mathrm{S}$ activity, homocysteine, and high-sensitivity C-reactive protein (Hs-CRP) [29].

\subsubsection{High-Risk Clinical Scenarios}

Selecting SLE patients for a coagulation assessment is well recognized for those with a thrombosis or fetal loss but is not well outlined for those who are at risk but have not yet had an
Table 17.2 High-risk lupus pregnancy

\begin{tabular}{l|l}
\hline \multicolumn{2}{l}{ High-risk lupus pregnancy } \\
\hline Renal involvement & High-dose steroid therapy \\
\hline Cardiac involvement & Pre-estrogen therapy \\
\hline $\begin{array}{l}\text { Pulmonary } \\
\text { hypertension }\end{array}$ & Pre-tamoxifen therapy \\
\hline Interstitial lung disease & Pre-organ transplantation \\
\hline Active lupus disease & Chronic inflammation \\
\hline Multiple pregnancy & Immobility \\
\hline $\begin{array}{l}\text { Pre-vascular } \\
\text { procedures } \\
\text { (stent placements, etc.) }\end{array}$ & $\begin{array}{l}\text { Immunosuppressive therapy } \\
\text { (cyclophosphamide, } \\
\text { methotrexate, etc.) }\end{array}$ \\
\hline $\begin{array}{l}\text { Extractable nuclear } \\
\text { antigens (Ro, La) }\end{array}$ & $\begin{array}{l}\text { Multiple antiphospholipid } \\
\text { antibodies }\end{array}$ \\
\hline
\end{tabular}

event. Therefore, patients who have had an event should obviously be selected for a coagulation workup. The high-risk scenarios which needed workup are given in Table 17.2.

\subsubsection{Management of Lupus Pregnancy}

Ideally, management of lupus pregnancy should begin before the onset of pregnancy. Thus, at preconception counseling, the physician not only estimates the risk profile of the patients but also reviews their drugs. The aim is to avoid known teratogenic drugs, to discontinue certain medications, and to initiate other drugs. This had been the golden goal to protect the mother and fetus from adverse effects of these medications. Hence, it is important to monitor the mother for at least 6 months before attempting conception. This is to assure a better outcome in lupus pregnancy.

There is a need for different subspecialists like rheumatologist, obstetrician, nephrologist, and neonatologist, to come together in managing such high-risk lupus pregnancy with close monitoring.

\section{A) Management Issues}

Once results are positive for pregnancy, we should have a baseline assessment of the disease activity, severity of the disease, and major organ involvement.

- Prenatal care visits: Every 4 weeks up to 20 weeks, then every 2 weeks until 28 weeks, and then weekly until delivery [Table 17.3]. 
Table 17.3 Guidelines in the assessment of pregnant patients with lupus

\begin{tabular}{|c|c|}
\hline \multirow[t]{7}{*}{$\begin{array}{l}\text { First } \\
\text { trimester }\end{array}$} & $\begin{array}{l}\text { - Baseline CBC, electrolytes, serum } \\
\text { creatinine, liver enzymes, uric acid. }\end{array}$ \\
\hline & $\begin{array}{l}\text { Fasting blood glucose, fasting lipid } \\
\text { profile if at high risk, for example, if } \\
\text { patient is nephritic or on steroids. }\end{array}$ \\
\hline & - Normal antenatal checkup. \\
\hline & $\begin{array}{l}\text { - ANA, anti-dsDNA, anti-Ro and } \\
\text { anti-La, antibody titers. }\end{array}$ \\
\hline & - Complements levels $\left(\mathrm{C}_{3}, \mathrm{C}_{4}, \mathrm{CH}_{50}\right)$. \\
\hline & $\begin{array}{l}\text { - Anticardiolipin antibodies, lupus } \\
\text { anticoagulant, and } \beta_{2} \text { glycoprotein. }\end{array}$ \\
\hline & $\begin{array}{l}\text { - Urinalysis, 24-hour urine collection } \\
\text { for measurement of protein and } \\
\text { creatinine clearance. }\end{array}$ \\
\hline \multirow{5}{*}{$\begin{array}{l}\text { Second } \\
\text { trimester }\end{array}$} & - Baseline laboratory studies. \\
\hline & - Anti-dsDNA. \\
\hline & $\begin{array}{l}\text { - Complement levels }\left(\mathrm{C}_{3}, \mathrm{C}_{4}, \mathrm{CH}_{50}\right) \text {, } \\
\text { urinalysis. }\end{array}$ \\
\hline & $\begin{array}{l}\text { - Obstetric ultrasound: Every } 4 \text { weeks } \\
\text { from } 20 \text { weeks of gestation until } \\
\text { delivery "to monitor fetal growth". }\end{array}$ \\
\hline & $\begin{array}{l}\text { Mother with positive anti-Ro and/or } \\
\text { anti-La antibodies, serial fetal } \\
\text { echocardiography between } 16 \text { and } \\
18 \text { weeks of gestation. }\end{array}$ \\
\hline \multirow{4}{*}{$\begin{array}{l}\text { Third } \\
\text { trimester }\end{array}$} & - Repeated laboratory studies. \\
\hline & $\begin{array}{l}\text { Urinalysis, 24-hour urine protein } \\
\text { collection if proteinuria is present. }\end{array}$ \\
\hline & $\begin{array}{l}\text { - Weekly fetal non-stress test (NST) } \\
\text { and/or biophysical profile (BPP) } \\
\text { scoring from } 28 \text { weeks gestation. }\end{array}$ \\
\hline & $\begin{array}{l}\text { - Fetal Doppler ultrasonography to be } \\
\text { done in presence of intrauterine } \\
\text { growth restriction. }\end{array}$ \\
\hline \multirow[t]{2}{*}{ Each visit } & - Careful blood pressure measurement. \\
\hline & - Urine dipstick for proteinuria. \\
\hline
\end{tabular}

Owing to the advancement of treatment interventions, more and more women with SLE are able to become pregnant. Pregnancy outcomes have improved noticeably over the last 40 years, with a decrease in pregnancy loss rate from a mean of $43 \%$ in $1960-1965$ to $17 \%$ in 2000 2003 [30].

Pregnant patients with SLE on immunosuppressive therapy should receive prophylaxis for infection (including antibiotics for invasive pro- cedures) and immunization with influenza and pneumococcal vaccine.

Other goals to achieve in managing a lupus pregnancy are:

1. Checking for high-risk clinical settings.

2. Performing coagulation risk lab profile in high-risk cases.

3. Assessment of the number and degree of procoagulant hits.

4. Prevention of thrombosis and adverse fetal outcomes.

5. Treatment of active lupus disease.

6. Treatment of hypercoagulable state.

7. Ensuring safety of medications used in treatment of the disease.

Treatment of hypercoagulable state:

1. Thromboprophylaxis for acute high-risk conditions.

2. Chronic prophylaxis for thrombosis prevention.

3. Full treatment dose anticoagulation therapy for thrombosis.

Thromboprophylaxis is controversial for patients with positive antiphospholipid antibodies (aPLs) but without any clinical history of thrombosis. However, evaluating risk of thrombosis by evaluating the multiple hits with a full thrombophilia profile would provide good support for deciding on intensity and type of thromboprophylactic treatment. For example, in pregnant SLE patients who are positive for lupus anticoagulant, it is recommended to use low-dose molecular weight or unfractionated heparin during pregnancy because neither can cross the placenta [31].

Treatment for acute arterial or venous thrombosis consists of an initial course of unfractionated or low molecular weight heparin followed by long-term treatment with warfarin to keep the international normalized ratio (INR) between 2.0 and 3.0. Heparin-type drugs or, more recently, 
one of the newer thrombin or factor Xa inhibitors can be used. For arterial thrombosis (stroke, myocardial infarction), addition of antiplatelet agents (low-dose aspirin, clopidogrel $75 \mathrm{mg}$ ) may be helpful, particularly if platelet hyperfunction is present [32]. Treatment for antiphospholipid syndrome (APS) is detailed in the section of antiphospholipid syndrome.

\section{B) Treatment of Active Lupus Activity}

SLE is common in women in the childbearing age. Physicians should be competent in the safe use of medications at preconception, conception, and during lactation. They should also be competent in addressing the effects of certain drugs on infants. The Food and Drug Administration (FDA) has a classification system for pregnancy risk. The pharmacological management of SLE could be puzzling as it has an unpredictable clinical course, with different organ system involvement and the absence of clear understanding of disease pathogenesis [33].

As hypertensive disorders of pregnancy are the leading cause of maternal mortality and morbidity, the target blood pressure of less than $140 / 90$ is to be achieved. The safer antihypertensive drugs in pregnancy based on the evidence relate to parenteral hydralazine or labetalol and oral labetalol, nifedipine, or methyldopa [34]. Treatment with low doses of aspirin during pregnancy would be indicated in women with SLE, APS, hypertension, history of preeclampsia, and renal disease. Low dose of aspirin is safe throughout pregnancy. Women who took aspirin had a significantly lower risk of preterm delivery than those treated with placebo, but there is no significant difference in perinatal mortality [35].

NSAID should be used in the lowest effective dose and should be withdrawn before 8 weeks of expected date of delivery [36]. Nevertheless, because of the shared character of inhibition of prostaglandin synthesis, adverse effects like constriction of the ductus arteriosus in utero, renal dysfunction in the neonate, persistent pulmonary hypertension, increased maternal blood loss, and prolongation of pregnancy and labor are all possible when administered to pregnant patients.
Hydroxychloroquine (HCQ) is now considered an extremely essential therapeutic choice in the treatment of lupus. These drugs are highly effective for discoid lupus erythematosus (DLE) cutaneous lesions. HCQ improves photosensitive skin lesions and prevents lupus flares [37]. Studies have confirmed that HCQ can preclude renal and central nervous system lupus. It also exerts the role of a prophylactic agent against some of the major comorbidities of SLE and its treatment, namely, hyperlipidemia, diabetes mellitus, and thrombosis [38]. More recently, chloroquine and HCQ have been shown to improve survival in a cohort of 232 SLE patients after adjusting for patient characteristics and disease activity [39]. It has been recently suggested that HCQ may affect TLR9 (toll-like receptor 9) activation and IFN-alpha production. From all of these perspectives, this drug is now considered an extremely essential therapeutic choice in the management of lupus.

Steroids are used in pregnant SLE, and safety is not a major concern for their use in pregnancy based on the clinical indication. But one needs to look into the maternal morbidity it causes like maternal hypertension, gestational diabetes, infection, weight gain, acne, and proximal muscle weakness. Consequently, close monitoring is essential with the use of the lowest possible dose of corticosteroid needed to control disease flare along with vitamin D and calcium supplement [40].

There are few immunomodulator drugs that are used in SLE patients such as cyclophosphamide, methotrexate, mycophenolate mofetil, cyclosporine, azathioprine, and rituximab. The use of these drugs needs a thorough discussion with the pregnant lupus patient before starting them. As most of these drugs are classified by FDA as pregnancy risk category B and few as category $\mathrm{X}$ or $\mathrm{D}$, they need to be shifted to azathioprine which is found to be safe in pregnancy [41]. Plasmapheresis and intravenous immunoglobulin (IVIG), the other two modalities of treatments used in lupus patients, are safe in pregnancy, but they are costly with very few indications. 


\section{C) Delivery}

SLE is not an indication for delivery by cesarean section, and one should allow for vaginal delivery as much as possible [42]. There should be a team approach to the pregnant women with SLE. This is to guarantee a safe vaginal delivery and allow performing a cesarean section for obstetric indications only. The indications for cesarean section are the same as in other conditions.

\section{D) Puerperium}

The optimum management does not stop with the birth of a healthy baby. Actually, postpartum period should be addressed as high risk for pregnant lupus patients with several possible complications. The mother can suffer a lupus flare. Several studies have confirmed the postpartum period is specifically high risk for increased lupus activity. A close surveillance in the first 4 weeks after delivery is thus warranted, especially in patients with recent activity or with a previous history of severe disease. However, no specific prophylactic therapy, such as increasing the dose of steroid, is recommended. Thromboembolic risk is also high during the puerperium [43].

SLE is a chronic multisystem disease occurring in young women in their childbearing age. Therefore, the collaboration of rheumatologists and obstetricians who are experienced in highrisk pregnancies management is essential for managing pregnant patients with SLE. The aim is to have successful outcomes for both the disease and the pregnancy. Some manifestations of normal pregnancy can be misinterpreted as signs of lupus activity. Thus, understanding of pregnancy and lupus interaction has resulted in better approaches of monitoring and treating this particular clinical condition.

\subsection{Antiphospholipid Syndrome in Pregnancy}

\subsubsection{Introduction}

APS or Hughes' syndrome is a multisystem autoimmune disorder with hypercoagulable state characterized by thrombosis (arterial, venous, or small blood vessels) or some obstetric complications (recurrent spontaneous abortions, stillbirth, preterm delivery, or severe preeclampsia) in the presence of antiphospholipid antibodies [44]. In $50 \%$ of the cases, it is primary (PAPS), and in the rest, it is secondary (SAPS) to any autoimmune disease particularly SLE.

APS is the most common cause of acquired thrombophilia and is a known risk factor for the development of deep vein thrombosis (DVT) with or without pulmonary embolism, new strokes in individuals below the age of 50, and recurrent fetal loss [45]. APS is seen in $0.5 \%$ in the general population and $1-5 \%$ in healthy women of childbearing age. The antiphospholipid antibodies are present in $30-40 \%$ of SLE patients, and up to a third of these patients develop clinical manifestations of APS, especially venous or arterial thromboses. Majority of these patients $(85-90 \%$ of the cases) are seen in the females in the reproductive age group [46].

\subsubsection{Diagnostic Criteria}

The 1999 Sapporo criteria is replaced by revised Sydney criteria in 2006. Since then many research work was done, but the criteria remain the same as in 2006 [47].

The clinical criteria include any of the followings:

1. Vascular (arterial, venous, or small vessel) thrombosis excluding superficial thrombosis.

2. Pregnancy morbidity.

(a) $\geq 1$ unexplained deaths of a morphologically normal fetus at or beyond $\geq 10$ gestational weeks $(\mathrm{GW})$

(b) $\geq 1$ premature births of a morphologically normal neonate $\leq 34 \mathrm{GW}$ due to severe preeclampsia, eclampsia, or severe placental insufficiency

(c) $\geq 3$ unexplained consecutive spontaneous abortions stenth GW (Excluding anatomic or hormonal defects or maternal/ paternal chromosomal causes). 
The laboratory criteria include the presence of any one of the three antibodies on two occasions at least 12 weeks apart. They are lupus anticoagulant (LA), anticardiolipin antibodies (aCL-IgG or $\operatorname{IgM})$, or anti- $\beta_{2}$-glycoprotein 1 antibody $\left(\mathrm{a} \beta_{2} \mathrm{GP} 1-\mathrm{IgG}\right.$ or $\left.\operatorname{IgM}\right)$. LA is to be tested 2-3 weeks after discontinuation of warfarin.

One clinical criteria and one antibody test are required for diagnosis of APS.

The aPL should be in medium or high titers at least tested twice $>12$ weeks apart. The strict objective criteria laid down for each clinical criterion should be fulfilled for the diagnosis of APS. aPLs are not only seen in APS (primary or secondary) but also in other diseases (syphilis, Lyme disease, CMV, EBV, HIV, HCV, and varicella) or patients on phenothiazines or even in normal general population. Therefore, the tests for aPL need to be repeated and established that these aPLs are persistently elevated and in medium or high titers to separate the APS patients from other causes of elevated aPL [47].

\subsubsection{Pathogenesis of APS}

Thrombotic and non-thrombotic mechanisms (inflammatory complement mediated) were proposed to explain the clinical manifestations in obstetric APS. In the last decade, the nonthrombotic mechanism proved to be the most important one causing cellular activation of endothelial cells, neutrophils, monocytes, and platelets leading to upregulation of tissue factor (TF) ultimately activating the coagulation pathway [48].

Obstetric APS complications are explained by three mechanisms:

\subsubsection{Thrombosis (Thrombosis of Vessels and Placenta)}

The main target antigens described in patients with APS include anti- $\beta 2 \mathrm{GP} 1 /$ cardiolipin, prothrombin, and annexin $\mathrm{V}$ which accounts for more than $90 \%$ of antibody-binding activity. The other targeted antigens are thrombin, protein $\mathrm{C}$, protein $\mathrm{S}$, thrombomodulin, tissue plasminogen activator, kininogens, prekallikrein, factor VII/
VIIa, factor XI, factor XII, complement component $\mathrm{C} 4$, heparan sulfate proteoglycan, heparin, and oxidized low-density lipoproteins [49].

Negatively charged phospholipids exposed on the outer side of cell membranes attract the main autoantigens. This is happening excessively under special circumstances such as injury, apoptosis (e.g., endothelial cell), or after activation (e.g., platelets) [49]. The aPL acts on the clotting regulatory proteins like annexin A5, prothrombin, factor $\mathrm{X}$, protein $\mathrm{C}$, and plasmin, thereby promoting thrombosis [50]. Anti- $\beta 2 \mathrm{GP} 1$ disrupts the anticoagulant annexin A5 shield on trophoblast and endothelial cell monolayers causing a procoagulant state which subsequently leads to infarction and thrombosis of the placenta [49]. The activated platelets by aPL lead to increased expression of GPIIb/IIIa followed by synthesis of thromboxane A2 thereby causing a procoagulant state [51].

\subsubsection{Defective Placentation}

Defective placentation is either due to impairment of invasion of trophoblast or inhibition of endometrial angiogenesis. Anti- $\beta 2 \mathrm{GP} 1$ is the most important antibody responsible for this mechanism. This antibody directly binds to the maternal decidua causing exposure of the cell membrane of the syncytiotrophoblast followed by injury, apoptosis, inhibition of proliferation, and formation of syncytia [52]. This results in defective secretion of growth factors and decreased production of human chorionic gonadotropin (HCG), thereby causing impaired invasion of trophoblast [52]. The aPL binds to human endometrial epithelial cells (HEEC) on maternal side inhibiting angiogenesis [53]. Endometrial angiogenesis and decidualization are fundamental prerequisites for successful implantation and placental development.

\subsubsection{Inflammation}

A physiological development of pregnancy requires a fine regulation of the maternal immune response during implantation of embryo. Acute inflammatory events are recognizable causes of adverse pregnancy outcomes through proinflammatory mediators, such as complement, tumor 
necrosis factor-alpha (TNF-alpha), and chemokines [54].

The aPLs induce an inflammatory response leading to compliment activation (both classical and alternate pathways with excessive generation of $\mathrm{C} 3 \mathrm{a}$ and $\mathrm{C} 5 \mathrm{a}$ ), activation of endothelial cells and monocytes, upgrading of $\mathrm{TF}$ and release of inflammatory mediators like intracellular adhesion molecule (ICAM), vascular cell adhesion molecule (VCAM), selectins, TNF-alpha, and interleukins (ILs) resulting in poor pregnancy outcome [55]. A new probable mechanism of aPL-mediated fetal loss linking TF and complement activation has been recently explained. TF, best known as the primary cellular initiator of blood coagulation, also contributes to different biological processes. Although APS is a thrombophilic disorder, it needs a triggering factor popularly known as "second hit" (inflammation, tobacco, estrogens, etc.) to complete the cascade of thrombosis [56].

PAPS is a hereditary condition without a known cause and more often seen in patients with genetic marker HLA-DR7. SAPS is secondary to a known autoimmune disease, out of which the commonest is SLE. Other diseases where it could also be seen are rheumatoid arthritis, scleroderma, Sjogren's syndrome, Behcet's disease, psoriatic arthritis, and temporal arteritis. It is also common in individuals with genetic markers: HLA-B8, HLA-DR2, and HLA-DR3, and it is also seen more in blacks, Hispanics, and Asians [57].

\subsubsection{Treatment}

\subsubsection{Low-Dose ASA (LDA): Either Alone or Combined with Heparin}

Pregnant women with aPL positivity should be stratified in order to administer the optimal treatment. The recommended treatment of established APS in pregnancy generally consists of aspirin combined with heparin. LMWHs are at least as effective as unfractionated heparin and are safer [58]. The rationale of this combination is that aspirin may inhibit aPL-mediated hypercoagu- lopathy in the intervillous space of the placenta. Heparin on the other hand may prevent aPLs from interfering with cytotrophoblast migration and promote blastocyst implantation in addition to prevention of venous thrombosis [59].

Prophylaxis and treatment of pregnancy with positive aPLs are shown in the flow chart (Fig. 17.1).

\subsubsection{Aspirin/Heparin-Resistant APS (AHR-APS)}

At least $20 \%$ of the patients do not respond to the recommended treatment, and there is no approved treatment for this group of patients. Nevertheless, since recurrence of thrombotic events occurs despite the therapy and thrombosis cannot account for all of the histopathological findings in placenta from women with APS, other suggested mechanisms of reproductive impairment were expected to be involved [60] in obstetrical APS. The most essential mechanism for heparin to protect placenta in APS emerges to be its ability to prevent the binding of aPL antibodies to trophoblast cells. Recent studies showed that heparin also acts by inhibiting the endometrial angiogenesis and now several trials go on to demonstrate the beneficial effects of neutralizing antibodies by using synthetic peptides using $\beta 2 \mathrm{GPI}$ epitopes [61].

The AHR cases, which are approximately $20 \%$, need to be approached differently. If they are resistant to conventional treatment of aspirin and heparin (unfractionated), it is better to give LMWH, particularly tinzaparin, which is found to be more effective or switch to fondaparinux with vitamin D supplements. If still not effective, the next step is to add high-dose HCQ (400$800 \mathrm{mg} /$ day) or low-dose prednisolone (10$15 \mathrm{mg} /$ day). Further resistance is counteracted by adding prednisolone to HCQ. If it is found still to be ineffective, then add pentoxifylline or IVIG in order for the treatment to be more effective.

Apart from these drugs, there are others which are being tried in resistant cases of APS. These include the combination of antiplatelet agents like aspirin and dipyridamole (adenosine uptake inhibitor), rituximab, homocysteine, direct thrombin inhibitors (dabigatran), oral direct fac- 
Fig. 17.1 Flow Chart for Management of Aps Pregnant Patient (R. Handa, 2006) (aCL=anti-cardiolipin antibody; LA=lupus anticoagulant; $\alpha \beta 2 \mathrm{GP} 1=$ anti $-\beta 2-$ Glycoprotein 1 antibody; $\mathrm{HCQ}=$ Hydroxy Choloroquin; anti-TNF drugs = Anti-Tumor Necrotic Factor drugs; IVIG=Intravenous Immunoglobulin)

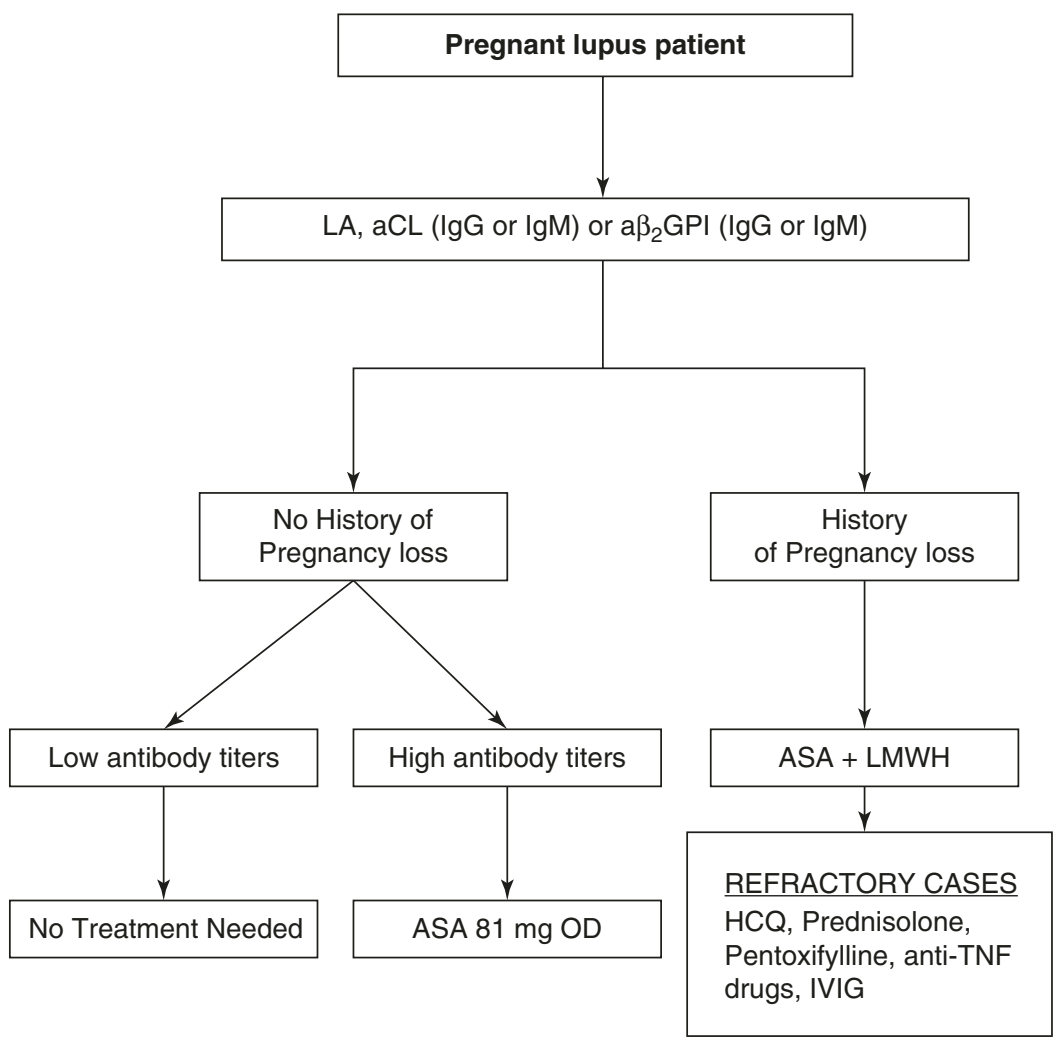

Recently inflammatory theory is gaining more importance, and accordingly management by drugs other than aspirin with heparin seems to play a prominent role in the future. However, this requires well-designed double-blind placebocontrolled randomized trials.

\subsection{Neonatal Lupus Erythematosus}

APS is a preventable and treatable thrombophilic multisystem autoimmune disorder causing two clinically important manifestations, namely, thrombosis and obstetric complications like recurrent consecutive spontaneous abortions, stillbirths, premature deliveries, and pregnancyinduced hypertension. It is a commonly prevalent disorder which needs high index of suspicion to diagnose early and offer prophylactic and therapeutic management. The cornerstone of management is low-dose aspirin with or without heparin based on the popular theory of thrombosis.

\subsubsection{Introduction}

Neonatal lupus erythematosus (NLE) or neonatal lupus syndrome is a rare syndrome seen in 1-2\% of neonates with autoantibodies to SSA/Ro, SSB/ La, and/or U1 RNP passively transferred transplacentally from the mother. Such a mother is either asymptomatic or having manifestations of SS, SLE, or other systemic rheumatic disease. NLE is distinguished by cutaneous, cardiac, or rarely both clinical manifestations. 


\subsubsection{Pathogenesis and Clinical Features}

The skin manifestation is appreciated at least in $30 \%$ of these patients. This may present in the form of periorbital annular erythematous plaques later spreading to other areas of the face, scalp, trunk, and extremities. It is non-scarring and nonatrophic and usually transient lasting for days to months. The cardiac manifestation is seen in up to $60 \%$ of the patients. It is mainly in the form of complete congenital heart block (CHB). This is irreversible and associated with cardiomyopathy in at least $10 \%$ of the cases. CHB is also associated with higher morbidity and mortality. Almost all the patients with cardiac lupus require permanent pacemaker. The recurrence rate of NLE is as much as $25 \%$ in the following pregnancies. There has been better understanding of etiopathogenesis of the disease in the recent past due to rapid development in field of medicine [64].

NLE is presumed to result from transplacental passage of maternal anti-SSA/Ro and/or antiSSB/La autoantibodies. These autoantibodies enter the myocardial cell resulting in exaggerated apoptosis. This leads to expression of these antibodies on the surface of the cardiocyte. It is postulated that resident cardiocyte participates in physiologic clearance of apoptotic cells. However, clearance is now inhibited by opsonization through these maternal autoantibodies. This results in accumulation of these apoptotic cells promoting inflammation and stimulating macrophages. Consequently, these macrophages secrete cytokines mainly transforming growth factor-beta (TGF- $\beta$ ) that stimulate fibroblast proliferation. Ultimately, this leads to fibrosis of the conduction system (causing CHB) or myocardium (leading to cardiomyopathy or endocardial fibroelastosis) or both [65, 66].

Presentation in the neonate could be in the form of bradycardia, intermittent cannon waves in the neck, varying intensity of first heart sound, intermittent gallops, and murmurs. The newborn is at greatest risk with a rapid atrial rate, often 150 beats/min or faster, and a ventricular rate less than 50 beats/min with junctional or atrioventricular (AV) nodal escape or ectopic rhythm. First- or second-degree heart block found in infants at birth can progress to $\mathrm{CHB}$ [67]. It may take just 1 week for a neonate to develop CHB from a normal PR interval. Therefore, weekly fetal echocardiography is essential between 16 and 24 weeks. The diagnosis of NLE is made when a fetus or newborn of a mother with anti-SSA/Ro and/or anti-SSB/La or anti-RNP antibodies develops heart block and/or the typical rash or hepatic or hematologic manifestations in the absence of other causes.

Women who test positive for SSA/Ro and $\mathrm{SSB} / \mathrm{La}$ autoantibodies may benefit from more intense evaluation for fetal heart block. This requires frequent fetal echocardiographic testing weekly from the 16th through the 26th week of pregnancy and then every other week until 32 weeks. The most vulnerable period for the fetus is during the period from 18 to 24 weeks gestation. Normal sinus rhythm can progress to complete block in 7 days during this high-risk period. New onset heart block is less likely from 26 to 30 weeks, and it rarely develops after 30 weeks of pregnancy. Fetoscope auscultation to detect heart blocks by detecting bradycardia, biophysical profile scoring, and non-stress testing can also be used to diagnose CHB [68].

\subsubsection{Treatment of Congenital Heart Block}

The ultimate treatment for $\mathrm{CHB}$ is prevention as once it is diagnosed, medical treatment seems to be less favorable. Testing for culprit antibodies is essential prior to initiating therapy for a presumed case of neonatal cardiac lupus (NCL) as there are cases of heart block not associated with anti-SSA/Ro and SSB/La antibodies. The incidence of CHB is only $2 \%$ in the offspring of unselected anti-Ro antibody positive mothers. Therefore, the preventative therapy cannot be recommended for this group. Yet, in women with a previous child with $\mathrm{CHB}$, the risk is greater, in the range of 17-19\%. Graham Hughes has suggested that in this group of patients, maternal administration of intravenous immunoglobulins (IVIG) may cut the risk of recurrences. Another 
possible strategy to avoid recurrence in subsequent pregnancies is immune suppression with fluorinated steroids, which cross the placenta. However, the toxicity of these agents prevents their use as a preventative therapy [69]. A casecontrol study proposed that using HCQ, a toll-like receptor (TLR) inhibitor may decrease the risk of $N C L$ related to anti-SSA/SSB antibodies [67].

Treatment of different degrees of heart blocks is variable. Complete heart block is permanent, and nothing could reverse it even with glucocorticoid therapy [70]. On the other hand, seconddegree heart block may be reversible. Unfortunately, it may progress to complete heart block despite therapy [71]. The clinical consequence of first-degree heart block is uncertain, since development from first-degree block to more advanced heart block in untreated fetuses has not been reported.

Fluorinated glucocorticoids such as dexamethasone and betamethasone, which are not inactivated by placental 11-beta hydroxysteroid dehydrogenase, may suppress the associated pleuropericardial effusion or hydrops and may improve outcomes. Fluorinated glucocorticoids are also considered for signs of a more global cardiomyopathy. Maternal dexamethasone in conjunction with transplacental $\beta$-adrenergic stimulation for bradycardia in fetus with $\mathrm{HR}$ of $<55$ beats/mt was reported to be effective in CHB [67].

Many children with CHB (33-53\%) require pacing as newborns. There is a long-term risk of sudden death. From this perspective, the majority of patients are paced by the time they reach adult life [72]. Neonatal cutaneous lupus requires mainly avoidance of sun exposure and use of sunblock and hydrocortisone cream. There is usually no need for systemic steroids in these patients. Systemic antimalarials, on the other hand, are not recommended due to slow onset of action in a transient illness and due to its potential toxicity in infants [73].

\subsubsection{Conclusion}

NLE is due to passive transplacental transfer of maternal IgG autoantibodies (SSA/Ro, SSB/La or U1RNP) to the fetus. It is seen in $1-2 \%$ of these neonates. It can cause transient and selflimiting cutaneous lupus that usually does not require treatment. It can also manifest as $\mathrm{CHB}$ which is usually permanent requiring pacemaker in most of the patients. They are susceptible for cardiomyopathy either as a direct effect of the disease or due to right ventricular pacing which also adds to mortality at least by $10 \%$. The diagnosis is made by identifying autoantibodies to SSA or SSB or U1 RNP in the mother. The diagnosis of CHB is made mainly in utero by periodic fetal echocardiography from 16 weeks onwards.

The outcome of heart blocks in general is not a favorable one. The mortality is considered high among children with CHB detected in utero than those detected after birth. The mortality is high mainly in the first year and particularly more in the first 3 months of life. Many aspects of the pathogenic mechanisms are discovered, but more research is needed. This is to help prevent this disease and provide better therapies for these patients.

\subsection{Rheumatoid Arthritis (RA) and Pregnancy}

\subsubsection{Introduction}

Rheumatoid arthritis (RA) is an autoimmune disease that is favorably influenced by pregnancy but classically flares after delivery [74]. The restructuring effect of pregnancy on RA has been well-known since 1938. Improvement of RA symptoms usually occurs in the first trimester and probably increases as pregnancy advances.

\subsubsection{Effect of Pregnancy on RA}

Pregnancy and postpartum period associated with changes in sex hormone levels, glycosylation of immunoglobulins, and cortisol level. One of the important immunological modifications during pregnancy is the $T h_{1} / T h_{2}$ shift. This is happening because of the progressive increase of progesterone and estrogens during pregnancy. 
They reach their peak level in the third trimester of gestation. At high levels, estrogens seem mainly to suppress $\mathrm{Th}_{1}$ cytokine and stimulate $\mathrm{Th}_{2}$-mediated immunological responses as well as antibody production. For this reason, $\mathrm{Th}_{1}$-mediated diseases, like RA, tend to improve [75]. Also changes in the percentage of $\mathrm{IgG}$ molecules lacking the terminal galactose units in the oligosaccharide chains attached to $\mathrm{H} 2$ regions have been tested as a probable explanation for ameliorating of RA during pregnancy. The percentage of agalactosyl IgG (Gal-o) varies with the age in normal healthy individuals. However, in patients with RA, Gal-o levels exceed normal values [76]. The levels of the glucocorticoids closely follow with the clinical improvement of RA in pregnancy. There is a progressive rise in total plasma cortisol levels with advancing gestation. The plasma concentration of free/active form of cortisol almost doubles in pregnant females as compared to the non-pregnant ones [77].

\subsubsection{Effects of RA on Pregnancy}

Women with well-controlled RA have a pregnancy outcome that is equivalent to the general obstetric population. Furthermore, disease activity and prednisone use during pregnancy were both adversely associated with birth weight. Only higher disease activity was associated with a lower birth weight, whereas the effect of prednisone on birth weight was mediated by shortening of the gestational age at delivery $[1,78]$. The short- and long-term desirability of pregnancy needs to be always considered in women with RA in their reproductive age. This is extremely vital while choosing disease-modifying antirheumatic drugs (DMARDs). Educating both women and men about appropriate contraception is a key to avoiding unplanned pregnancies while taking a DMARD that is teratogenic and/or has unknown safety profile during pregnancy. A strategy for RA management during pregnancy is necessary as well for the health of the mother to reduce possible toxicity to the fetus [79].
The safe strategy to be used in managing RA in those planning pregnancy is as follows:

(a) Patients in remission-Review and adjust the medications compatible with pregnancy.

(b) Patients with active disease-Delay pregnancy till improvement is achieved with adequate treatment.

In RA, antepartum evaluation should include in addition to detailed history and musculoskeletal examination a careful examination of upper airway and cervical spine. A lateral cervical spine radiograph should be obtained in case a pregnant patient is affected by severe erosive disease or presence of neck symptoms or duration of the disease for more than 10 years. This film should be with flexed neck to exclude atlanto-axial anterior subluxation [80]. Extreme caution should be taken while managing the airway of these patients for any surgical intervention.

\subsection{Sjogren's Syndrome (SS) and Pregnancy}

Sjogren's syndrome (SS) is a chronic autoimmune inflammatory disease that can present either alone, primary Sjogren's syndrome (PSS), or in the context of an underlying connective tissue disease (secondary SS). It may occur at any age but mainly affects women in the fourth decade of life with a female-to-male ratio of 9:1 [32]. It is important to notice that the systemic form may be associated with other autoimmune disease, for example, RA in $30 \%$ of cases, SLE in $10 \%$, and scleroderma in $1 \%$ autoimmune thyroid disease, chronic hepatitis, or lymphatic system disorders. Furthermore, systemic SS is characterized by anti-Ro/SSA $70-80 \%$, and afflicted pregnancies may be exposed to high risk of CHB, cardiomyopathy, and neonatal lupus. These risks in some reports have been higher than in patients with SLE [81].

PSS can occur in all age groups, including children. Pregnancy complications due to the presence of anti-Ro/SSA and anti-La/SSB autoantibodies in the maternal serum are well recog- 
nized as NLE and CHB. Reports on pregnancy outcomes beyond these two disorders are rare in PSS in contrast to the situation in SLE and APS. Pregnancy outcome in PSS has not been thoroughly studied but has in overall not been considered to be associated with adverse fetal outcome [82]. Data on pregnancy outcome in PSS are few and conflicting. In the past decades, the paucity of reports maybe related to the fact that PSS doesn't usually become clinically apparent until the fourth decade of life. However, the advanced maternal age of the first pregnancy has been discovered recently to explain the increased impact on pregnancies complicated by PSS [83].

\subsection{Systemic Sclerosis (SSc) and Pregnancy}

Systemic sclerosis (SSc) is a chronic autoimmune disorder with approximate female-to-male ratio of 5:1. Reports of pregnancies in SSc are rare owing to the low prevalence of the disease. The onset of the disease is usually after the fourth decade of life [84]. Most physicians concur that SSc women have a high probability of successful pregnancy if careful planning, close monitoring, and appropriate therapy are implemented. Moreover, retrospective case-control studies showed less ominous outcomes [85]. Still, an increased occurrence of preterm births and small full-term infants, compared to the controls, was noticed. Symptoms related to SSc particularly Raynaud's phenomenon improves during pregnancy, but esophageal reflux worsens. After pregnancy, some women with diffuse SSc had increased skin thickening [85].

The exertional dyspnea is particularly worse in the third trimester as the uterus increases in size. It is essential to rule out pulmonary hypertension during preconception counseling [86]. The extreme danger in pregnant SSc women is the occurrence of renal crisis, secondary to acute onset severe hypertension that can be fatal for both mother and child. It can be puzzled with preeclampsia and HELLP syndrome. However, in contrast to preeclampsia, delivery of the fetus does not affect the hypertension or renal dysfunc- tion. Elevation of blood pressure in these patients, even mild, should be considered possibly serious, yet pregnancy itself does not appear to increase the risk of renal crisis.

Renal crisis is more prevalent in patients with early diffuse SSc (within 5 years from symptom onset). Risk factors include the presence of antitopoisomerase, anti-RNA polymerase III antibodies, and exposure to high doses of corticosteroids. Preeclampsia rate does not seem to be increased in SSc patients [85]. Angiotensinconverting enzyme inhibitors (ACEI) are a lifesaving treatment in hypertensive renal crisis in patients with SSc despite their association with congenital malformations and kidney dysfunction in the infant [86].

History of a renal crisis during a previous pregnancy should delay the following pregnancy until the disease has been stabilized. This usually takes around 3-5 years from the onset of symptoms. These women are usually treated with nifedipine to maintain good control of blood pressure. Delivery is usually recommended if appropriate antihypertensives fail. ACEI may be initiated during pregnancy in severe cases after appropriate counseling about the risk of congenital abnormalities [86]. High rate of complications during pregnancy is seen in women with history of significant interstitial lung disease, scleroderma renal crisis, early diffuse SSc with rapid onset, or moderate-severe pulmonary arterial hypertension (PAH).

If a patient with SSc wishes to continue with pregnancy after applicable counseling of risks, aggressive monitoring and co-management with experts in renal and pulmonary disease are mandatory. Medications such as ACEI and prostaglandins which conduct high risk for congenital malformations with higher incidence of other fetal toxicities need to be considered. The benefits to both mother and fetus may overshadow known risks of antenatal exposure [87]. Previous events of renal crisis are not a complete contraindication for future pregnancy. It is recommended that a woman postpone several years until her disease is stable before trying to conceive. A trial without ACEI prior to pregnancy is suggested to deter- 
mine if blood pressure can be effectively controlled with substitute antihypertensive medications [88].

Labor and delivery are susceptible period in these cases. Some patients may need prolonged observation in the hospital following delivery to monitor for acute cardiovascular collapse in case of PAH [87]. In SSc, a thorough search should be conducted for systemic dysfunction, namely, renal disease, systemic hypertension, PAH, cardiac dysfunction, and fetal distress. Close surveillance should be performed for arterial pulses, peripheral venous access, extent of Raynaud's involvement, and special positioning needs [80].

\subsection{Vasculitis and Pregnancy}

\subsubsection{Introduction}

There are profound immune and endocrine changes which happen during pregnancy. The physiological increase of cortisol, progesterone, estradiol, and testosterone during the third trimester of pregnancy seems to lead to Th2 cytokine polarization both at systemic level and at the feto-maternal interface.

The following issues should be taken into consideration while counseling the patient with vasculitis for pregnancy:

(a) Patients should receive a mode of contraception at least while receiving high dose of cytotoxic medications.

(b) Pregnancies should be planned when the disease is in remission.

(c) Strict monitoring is recommended for patients during gestation and postpartum periods by multidisciplinary team.

(d) In case of disease relapse on adequate treatment, aggressive management should be recommended.

(e) Pregnancy complicated by the onset of vasculitis particularly has worse prognosis.

In patients with systemic vasculitis, the risk of thromboembolic events is increased [24].
Table 17.4 Effect of pregnancy on the course of systemic vasculitis [90]

\begin{tabular}{l|l|l}
\hline \multicolumn{2}{l}{ Status of disease at conception } \\
$\begin{array}{l}\text { Type of } \\
\text { vasculitis }\end{array}$ & Active & Inactive \\
\hline GPA & $\begin{array}{l}\text { Frequent flares-Risk of } \\
\text { maternal death }\end{array}$ & $\begin{array}{l}\text { Rare flares } \\
(25 \%)\end{array}$ \\
\hline PAN & Frequent flares & $\begin{array}{l}\text { Rare flares } \\
(25 \%)\end{array}$ \\
\hline MPA & Risk of maternal death & $\begin{array}{l}\text { Frequent } \\
\text { flares } \\
(50 \%)\end{array}$ \\
\hline EGPA & $\begin{array}{l}\text { Frequent flares (50\%) } \\
\text { (asthma, mononeuritis } \\
\text { multiplex, skin rash) }\end{array}$ & $\begin{array}{l}\text { Rare flares } \\
(25 \%)\end{array}$ \\
\hline TA & $\begin{array}{l}\text { High risk of maternal } \\
\text { morbidity and fatality in } \\
\text { patients with severe aortic } \\
\text { valvular diseases or aortic } \\
\text { aneurysm }\end{array}$ & $\begin{array}{l}\text { Rare flares } \\
(25 \%)\end{array}$ \\
\hline BD & $\begin{array}{l}\text { Frequent improvement (50\%) } \\
\text { Rare flares } \\
(25 \%)\end{array}$ \\
\hline
\end{tabular}

(GPA granulomatous polyangiitis, $P A N$ polyarteritis nodosa, MPA microscopic polyangiitis, EGPA eosinophilic granulomatous with polyangiitis, TA Takayasu's arteritis, $B D$ Behcet's disease)

\subsubsection{Large Vessel Vasculitis}

\subsubsection{Behcet's Disease (BD)}

Systemic vasculitides are infrequent diseases characterized by an abundant variety of symptoms, ranging from mild to life-threatening manifestations. Pregnancy is more frequent in vasculitis that have onset at younger age and affect the female gender such as Takayasu's arteritis (TA) and Behcet's disease (BD) [89, 90]. BD is an inflammatory disorder of unknown etiology that affects mostly young adults. It involves the oral and genital mucosae as well as the eyes, joints, and central nervous system (CNS). Furthermore, arterial and/or venous thrombosis also may occur during the course of BD. This has been connected with considerably increased morbidity. Limited data are available concerning the impact of pregnancy on the course of BD (Table 17.4) [90].

Although BD appears to improve during pregnancy, disease flare consists mainly of oral and genital ulcerations. Mucocutaneous ulcerations seem to predominate during the second 
and third trimesters of pregnancy. Lifethreatening complications such as thrombosis or CNS lesions can happen as well. The postpartum period is still a vulnerable period. The global risk of obstetric complications in patients with BD is similar to that in the overall population. However, the risk of miscarriage seems to be increased in patients with a history of vascular involvement. The use of colchicine is safe in pregnant women with $\mathrm{BD}$ and could even reduce the risk of disease flares. Other medications like azathioprine and glucocorticoids can also be used during pregnancy, seemingly without an increased risk of complications. Pregnancy is consequently a viable option for women who have $\mathrm{BD}$ [91].

BD activity may vary between pregnancies in the same patient. It has to be noted that remission and exacerbation both have been reported during pregnancy. Relapses occur most frequently in the first trimester. They represent primarily mucocutaneous findings with ocular and thrombotic complications being rare. Active disease does not seem to worsen maternal or fetal outcome. Maternal BD has not been linked to an increased rate of miscarriage, pre-maturity, fetal anomalies, or neonatal BD. Pregnant patients who suffer from genital ulcers at the time of delivery may benefit from cesarean section. Patients should continue to be monitored postpartum as the disease might flare according to several reports [92]. Pregnancy is a hypercoagulable state; therefore anticoagulation is recommended in women with prior history of thrombosis.

Most infants born to mothers with BD are generally healthy. Reports of neonatal BD have appeared infrequently in the literature. While some have proposed that the mechanism of disease of neonatal BD is similar to that of NLE, there is no evidence of any transplacental transfer or maternal antibodies [93]. Most of the reports of neonatal BD have portrayed a transient disease with spontaneous resolution [93].

\subsubsection{Takayasu's Arteritis}

TA is a granulomatous vasculitis that affects large vessels such as the aorta, its major branches, and pulmonary arteries. TA manifests at a younger age, typically affecting the women of childbearing age. Fertility appears not to be affected. Neither the fetal mortality nor spontaneous abortion rates are increased in TA, but the incidence of low birth weight is increased. Maternal complications include accelerated hypertension, heart failure, and stroke [94].

It is obligatory to tightly control blood pressure (BP) using both noninvasive (BP measurement at upper and lower limbs and Doppler flow if pulses are not palpable) and invasive procedures (intra-arterial monitoring through arterial cannulation). This is mandated particularly when $\mathrm{BP}$ values cannot be accurately measured due to multiple vascular stenosis. In order to prevent BP increase during vaginal pushing, spinal analgesia should be given, and BP monitoring should be continued at least $24-48 \mathrm{~h}$ after delivery. This is due to the hemodynamic changes that occur in the postpartum period which might promote aortic dissection.

Aortic valvular disease has been reported as a risk factor for maternal morbidity in patient with TA. The baseline cardiac function should be assessed at the onset of pregnancy and monitored through pregnancy [95]. In postpartum period, antibiotics should be given to prevent bacterial endocarditis in patients with aortic insufficiency and/or luminal narrowing of the aorta and its branches [89].

The indications for cesarean section in TA are mainly for [19]:

1. Obstetrical reasons.

2. Mild disease but with elevated systolic BP despite adequate medical treatment at the time of labor.

3. Presence of one or more complications like retinopathy, secondary hypertension, aortic insufficiency, aortic/arterial aneurysm, and non-recordable BP in both arms.

4. Severe complications of TA like heart failure or dysrhythmias.

Disease relapse during pregnancy are generally treated with prednisone $1 \mathrm{mg} / \mathrm{kg} / \mathrm{day}$ until the disease control is obtained. Then prednisone can be tapered to the lowest possible effective dose. In 
refractory cases, the use of azathioprine is recommended. Hypertension has to be managed very aggressively with $\propto-$ methyldopa, Ca-channel blocker, or hydralazine. ACEIs are contraindicated because of their high incidence of fetal toxicity [92].

\subsubsection{Medium Vessels Vasculitis}

\subsubsection{Polyarteritis Nodosa (PAN)}

PAN is a disorder characterized by necrotizing inflammation of medium size or small arteries. In patients with PAN, prevalent manifestations are general symptoms like malaise, fever and fatigue, musculoskeletal pain and arthralgias, mucocutaneous findings, and gastrointestinal manifestations [95]. Peripheral neuropathy especially mononeuritis multiplex is common as well [95]. Approximately $30 \%$ cases of PAN are associated with co-infection with hepatitis B. Like other forms of vasculitis, PAN can be associated with hypertension, abdominal pain, and proteinuria simulating some of the more common complications of pregnancy [90].

Some patients have a medium vessel vasculitis that is restricted to the skin. This form of vasculitis, known as cutaneous PAN, generally does not evolve to the systemic form [90]. Worsening of a mild form of vasculitis in a pregnant patient may be treated effectively with glucocorticoids alone. Use of cyclophosphamide is required in the presence of life-threatening manifestations particularly bowel infarction, CNS, and/or cardiac involvement [95].

\subsubsection{Small Vessels Vasculitis}

\subsubsection{Granulomatosis with Polyangiitis (GPA) (Wegner's Granulomatosis)}

Pregnancies in women with GPA are uncommonly observed. The disease peaks after the age of 40, and it affects mainly the upper respiratory tract, the lungs, and the kidneys. The relapse or worsening of renal involvement in the late pregnancy can be difficult to differentiate from preeclampsia. There are few useful parameters in this regard with active urine sediment indicating GPA nephritis [96]. Premature delivery is a common complication of pregnancy in patients with GPA, particularly in those with active disease during gestation. In case of insufficient response to corticosteroids, azathioprine can be used. Cyclophosphamide may be considered for life-threatening manifestations occurring during the second or third trimester of pregnancy [96].

\subsubsection{Eosinophilic Granulomatosis with Polyangiitis (Churg-Strauss Syndrome)}

Eosinophilic granulomatosis with polyangiitis (EGPA) formerly known as Churg-Strauss syndrome is a disorder characterized by pulmonary and systemic small vessel vasculitis, extravascular granulomas, and hypereosinophilia occurring in patients with asthma and allergic rhinitis [96]. Pregnancy is not a common event in EGPA due to various reasons such as the rarity of the disease, the peak incidence of the disease around the fifth decade, and male preponderance [97].

EGPA relapse was reported in $50 \%$ of women who conceived, while the disease was in remission. The commonly observed manifestations during the relapse were worsening of asthma, mononeuritis multiplex, and skin rash. Patients with disease onset during pregnancy are considered as unfortunate as they had a very poor prognosis. Cases of fulminant EGPA associated with pregnancy may be caused by decrease or discontinuation of the medications in use. This is in addition to the loss of lung capacity associated with pregnancy, which may further exacerbate the existing bronchospasm [90]. Treatment of EGPA relapses during pregnancy consists of the use of prednisone with adjusted doses according to the severity of disease manifestations. In EGPA patients, special care should be given to monitor bronchospasm during pregnancy and postpartum period [96]. 


\subsection{Polymyositis (PM)/ Dermatomyositis (DM) and Pregnancy}

Women in reproductive age group are rarely affected by PM/DM as the onset of the disease is over the age of 45 years. Data for such diseases are extremely limited. Patients are encouraged to achieve and maintain stable disease prior to conception. It is recommended obviously to have the disease totally quiescent as active muscle weakness adversely affects both pregnancy and labor. The typical guidelines applied while using medications during pregnancy in other rheumatic diseases should be applied again in these diseases. Medications that are contraindicated in pregnancy would need to be substituted prior to conception [1].

The fetal prognosis matches activity of the maternal disease. In patients with preexisting quiescent disease, little clear risk to the mother or fetus is observed. This is in contrast to new onset of disease or exacerbation during pregnancy for which a significantly worse outcome is noted [98]. Treatment with corticosteroids, azathioprine, and intravenous immunoglobulin may be suitable for active myositis during pregnancy. It is observed that patients with PM are sensitive to non-depolarizing muscle relaxants and the use for their antagonist drugs may cause muscle weakness and severe arrhythmias. Steroid-induced myopathy may lead to an increased sensitivity to neuromuscular blocking drugs and an unpredictable response. All these are important clinical vignettes that should be taken care of while dealing with these patients particularly during anesthesia. Other important aspects to be considered in the anesthetic management are respiratory insufficiency, risk of aspiration, arrhythmias, cardiac failure, and hyperkalemia [99].

Disease activity and underlying cardiopulmonary involvement should be thoroughly evaluated in affected patients with PM/DM. In the presence of muscle weakness, spirometry should be done to evaluate respiratory muscles involvement. Chronic aspiration due to pharyngeal weakness may lead to pulmonary diffusion deficits. An
ECG should be done to exclude conduction abnormalities and arrhythmias [80]. Echocardiogram and full cardiac evaluation may be required accordingly.

\subsection{Spondyloarthritis and Pregnancy}

Ankylosing spondylitis (AS) is a chronic, progressive autoimmune disease, mainly involving sacroiliac joint, vertebral column, and peripheral joints. It is also complicated with some other manifestations including uveitis and the aortic valve lesions in the heart $[100,101]$. Pregnancy may occur in patients with this disease as the peak incidence of AS is in the 25-34 years of age group [102]. Pregnancy has been observed to significantly improve peripheral arthritis and uveitis in most patients, but there is deterioration in $25 \%$ of patients with predominantly axial disease in pregnancy [100]. As with other rheumatic disease, there is an increased risk of flares in postpartum period [100].

Clinicians who are taking care of a pregnant patient with this disease need to be concerned for few issues. These include the method of delivery, the optimal choice of labor analgesia, and the type of anesthesia to be provided in the event of cesarean section. Possible pelvic joint ankylosis associated with AS can interfere with a normal spontaneous vaginal delivery. The potential cardiac involvement in AS may also have an influence on the mode of delivery. Although aortic regurgitation correlated with AS is often asymptomatic, even trivial valvular disease may cause decompensation in the pregnant patient. Other cardiac involvements in AS which have been reported include proximal aortitis, mitral regurgitation, and conduction defects. Preanesthetic evaluation should include a careful physical examination of the chest and cardiovascular systems as well as a baseline electrocardiogram. Transthoracic echocardiography may be used to evaluate the abnormal findings of the heart in the clinical examination [90]. However, it might be considered as a baseline for patients with long-lasting disease. 
Pulmonary involvement in AS have also been described. A restrictive pattern of lung function is seen due to costochondral rigidity and flexion deformity of the thoracic spine.

Placement of epidural anesthesia in these patients may be technically difficult. This could be related to calcification of interspinous ligaments, formation of bony bridges between the vertebrae, or ankylosis of the vertebral column with restriction in lumbar flexion. General anesthesia is sporadically necessary in patients with AS. Involvement of the cervical and temporomandibular joint or cricoarytenoid arthritis may cause obstacles with tracheal intubation. Moreover, loss of normal neck flexibility with increasing osteoporosis predisposes the spine to fracture, even with minor trauma. An awake fiberoptic intubation should be considered whenever a difficult intubation is anticipated or ankylosis of the spine is expected [102].

\subsection{Conclusion}

As rheumatic diseases affect women during the childbearing age, every pregnancy for those patients should be considered as high risk and should be strictly monitored by meticulous antenatal evaluation. It is essential to know the effect of each disease on pregnancy and vice versa. Therefore, the physician should focus on the prepregnancy planning, fertility, medications use, and fetal complications and need to continue the care through the postpartum and lactation periods.

Most of the complications of these diseases during pregnancy can be prevented. This can be achieved by carefully planning the pregnancy during the inactive phase of the disease and timely discontinuation of harmful medications used in these disorders. However, pregnancy can still be threatened by active disease, presence of autoantibodies, and severe affection of major organ involvement by the disease. Therefore, the management of these rheumatic diseases in pregnancy needs a multidisciplinary approach by the rheumatologist, obstetrician, neonatologist, and at times other specialists (nephrologist, hematol- ogist, etc.). This is to support these unfortunate patients from all dimensions to have a healthy child [103].

Acknowledgments The editors would like to thank Dr. Suvarna Raju Yelamanchili, MD. Consultant in Internal Medicine King Fahd Armed Forces Hospital, Jeddah, Saudi Arabia for his effort in developing this chapter.

\section{References}

1. Keeling S, Oswald A. Pregnancy and Rheumatic Disease, by the book or by the doc. Clinical Rheumato. 2009;28(1):1-9.

2. Jansen AJ, van Rhenen DJ, Steegers EA, Duvekot JJ. Postpartum hemorrhage and transfusion of blood and blood components. Obstet Gynecol Surv. 2005;60:663.

3. Lang RM, Borow KM. Heart disease. In: Barron WM, Lindheimer MD, editors. Medical Disorders During Pregnancy. St. Louis: Mosby Year Book; 1991. p. 184.

4. McColl MD, Ramsay JE, Tait RC, et al. Risk factors for pregnancy associated venous thromboembolism. Thromb Haemost. 1997;78:1183.

5. Talbert LM, Langdell RD. Normal values of certain factors in the blood clotting mechanism in pregnancy. Am J ObstetGynacol. 1964;90:44.

6. Lim KJH, Odukoya OA, Ajjan RA, et al. The role of T-Helper cytokines in human reproduction. FertilSteril. 2000;73:136-42.

7. Tilburgs T, Scherjon SA, Claas FH. Major histocompatibility complex (MHC)-mediated immune regulation of decidual leukocytes at the fetal-maternal interface. J ReprodImmunol. 2010;85:58.

8. Stojilkovic SS, Reinhart J, Catt KJ. Gonadotropinreleasing hormone receptors: structure and signal transduction pathways. Endocr Rev. 1994; 15:462.

9. Imperatore A, Florio P, Torres PB, et al. Urocortin 2 and urocortin 3 are expressed by the human placenta, decidua, and fetal membranes. Am J ObstetGynecol. 2006; $195: 288$.

10. Lønberg U, et al. Increase in maternal placental growth hormone during pregnancy and disappearance during parturition. Am J ObstetGynecol. 2003; $188: 247$.

11. Homsen JK, et al. Atrial natriuretic peptide (ANP) decrease during normal pregnancy as related to hemodynamic changes and volume regulation. Acta Obstet Gynecol Scand. 1993;72:103.

12. Villa-Blanco I, Calvo-Alen J. Utilizing Registries in Systemic Lupus Erythematosus Clinical Research. Expert Rev. 2012;8(4):353-60.

13. Dhar JP, et al. Lupus and pregnancy: complex yet manageable. Clin Med Res. 2006;4(4):310-21. 
14. Urowitz MB, Glabman DD, Farewell VT, Stewart J, McDonald J. Lupus and pregnancy studies. Arthritis Rheum. 1993;36(10):1392-7.

15. Jara LJ, et al. Bromocriptine during pregnancy in systemic lupus erythematosus: a pilot clinical trial. Ann NY AcadSci. 2007;1110:297-304.

16. Mascola MA, et al. Obstetric management of the high-risk lupus pregnancy. Rheum Dis Clin North Am. 1997;23:119-32.

17. Gayed, Gordon C. Pregnancy in rheumatic diseases. Rheumatology. 2007;46:1634-40.

18. Khamashta MA, Hughes GRV. Pregnancy in SLE. CurropinRheumatol. 1996;8:424-9.

19. Kong NC. Pregnancy of a lupus patient- a challenge to the nephrologist. Nephrol Dial, Transplant. 2006;21(2):268-72.

20. Georgion PE, Politi EN, Katsimbri P, Sakka V, Drosos AA. Outcome of Lupus pregnancy: a controlled study. Rheumatology (Oxford). 2000;39(9):1014.

21. Rahman EZ, et al. Pregnancy outcomes in lupus nephropathy. Arch GynecolObstet. 2005;271(3):222-6.

22. Arkel YS, Ku DH. Thrombophilia and pregnancy: review of the literature and some original data. Clin Appl Thromb Hemost. 2001;7(4):259-68.

23. Dhar JP, Essenmacher L, Ager J, Sokol RJ. Pregnancy outcomes before and after diagnosis of systemic lupus Erythematosus. American Journal of Obstetrics \& Gynecology.

24. De Laat B, Wu XX, van Lummel M, Derksen RHWM, de Groot PG, Rand JH. Correlation between antiphospholipid antibodies that recognize domain I of $\beta 2$-glycoprotein 1 and a reduction in the anticoagulant activity of annexin A5. Blood. 2007;109:1490-4.

25. Adams MJ, Palatinus AA, Harvey AM, Khalafallah AA. Impaired control of the tissue factor pathway of blood coagulation in systemic lupus erythematosus. Lupus. 2011;20:1474.

26. Bick RL. Recurrent miscarriage syndrome due to blood coagulation protein/platelet defects: prevalence, treatment and outcome results. DRW Metroplex Recurrent Miscarriage Syndrome Cooperative Group. Clin Appl Thromb Hemost. $2000 \mathrm{Jul} ; 6(3): 115-25$.

27. Devreese KMJ, Standardization of antiphospholipid antibody assays. Where do we stand? Lupus 2012 21: 718

28. Bertolaccini ML et al Non-criteria' aPL tests: report of a task force and preconference workshop at the 13th International Congress on Antiphospholipid Antibodies, Galveston, TX, USA, April 2010. Lupus 2011 20: 191

29. Dhar JP, Andersen J, Essenmacher L, Ager J, Sokol RJ. Thrombophilic Patterns of Coagulation Factors in Systemic Lupus Erythematosus. Lupus. 2009; 18:400.

30. Ca $\mathrm{C}$, et al. Decrease in pregnancy loss rates in patients with systemic lupus erythematosus over a 40-year period. J Rheumatol. 2005;32:1709-12.
31. Dhar JP, Sokol RJ. Lupus and Pregnancy: Complex Yet Manageable. Clinical Medicine \& Research. 2006;4(4):310-20.

32. Tripodi A, deGroot PG, Pengo V. Antiphospholipid syndrome: laboratory detection, mechanisms of action and treatment. J Intern Med. 2011;270:110-22.

33. Francis L. Pharmacotherapy of systemic lupus erythematosus. Expert Opin Pharmacother. 2009;10(9):148-94.

34. Magee LA, Sibai B. (2011). How to manage hypertension in pregnancy effectively British Clinical Pharmacol. https://doi.org/10.111/j:1365-2125.

35. Kozer E, et al. Effects of aspirin consumption during pregnancy on pregnancy outcomes: metaanalysis. Birth defects Res B Dev Reprod Toxicol. 2003;68(1):70-84.

36. Ostensen ME, et al. Optimisation of antirheumatic drug treatment in pregnancy. Clinical Pharmacokinetics. 1994;27(6):486-503.

37. Gladman DD, Urowitz MB, Senecal JL, et al. Aspects of use of antimalarials in systemic lupus erythematosus. Journal of Rheumatology. 1998;25(5):983-5.

38. Mpetvi. Hydroxychloroquine use in the Baltimore lupus cohort: effects on lipids, glucose and thrombosis. Lupus. 1996;5(supp.1)

39. Tektonidou MG, et al. Risk factors for thrombosis and primary thrombosis prevention in patients with systemic lupus erythematosus with or without antiphospholipid antibodies. Arthritis Rheum. 2009;61:29-35.

40. Raybum WF. Glucocorticoid therapy for rheumatic disease: maternal, fetal and breastfeeding considerations. American Journal of Reproductive Immunology. 1992;28(3-4):138-40.

41. Da Boer NK, Jarbandhan SV, de Gra FP. Azathioprine use during pregnancy: unexpected intrauterine exposure to metabolites. AmjGastroenerology. 2006;101(6):1390-2.

42. Fredrick J. Pregnancy complications and delivery practice in women with connective tissue disease and inflammatory rheumatic disease in Norway. AOGS. 2000;79(6):490-5.

43. Riuz-Irastorza G, et al. Managing lupus patients during pregnancy. Best Practice \& Research, Clinical Rheumatology. 2009;23:575-82.

44. Branch DW, Khamashta MA. Antiphospholipid syndrome: obstetric diagnosis, management, and controversies. Obstet Gynecol. 2003;101(6):1333-44.

45. Ginsburg KS, Liang MH, Newcomer L, et al. Anticardiolipin antibodies and the risk for ischemic stroke and venous thrombosis. Ann Intern Med. 1992;117:997-1002.

46. McClain MT, Arbuckle MR, Heinlen LD, et al. The prevalence, onset and clinical significance of antiphospholipid antibodies prior to diagnosis of systemic lupus erythematosus. Arthritis Rheum. 2004;50:1226-32.

47. Miyakis S, et al. International consensus statement on an update of the classification criteria for definite antiphospholipid syndrome (APS). J ThrombHaemost. 2006;4:295-306. 
48. Lakos G, et al. International consensus guidelines on anticardiolipin and anti-beta(2) glycoprotein I testing: A report from the APL task force at the 13(th) international congress on antiphospholipid antibodies. Arthritis Rheum 2011. https://doi.org/10.1002/ art.33349.

49. Csepany T, et al. MRI findings in central nervous system systemic lupus erythematosus are associated with immunoserological parameters and hypertension. J Neurol. 2003;250(11):1348-54.

50. Lindqvist P, Dahlback B, Marsal K. Thrombotic risk during pregnancy: a population study. ObstetGynecol. 1999;94(4):595-9.

51. Pabinger I, et al. Temporary increase in the risk for recurrence during pregnancy in women with a history of venous thromboembolism. Blood. 2002;100(3):1060-2.

52. Galli M, et al. Anticardiolipin antibodies (ACA) directed not to cardiolipin but to a plasma protein cofactor. Lancet. 1990;335(8705):1544-7.

53. Branch DW, et al. A multicenter, placebo-controlled pilot study of intravenous immune globulin treatment of antiphospholipid syndrome during pregnancy. The Pregnancy Loss Study Group. Am J Obstet Gynecol. 2000;182(1 Pt 1):122-7.

54. Pierangeli SS, et al. Antiphospholipid antibodies and the antiphospholipid syndrome: pathogenic mechanisms. Semin Thromb Hemost. 2008;34(3):236-50.

55. Permpikul P, Rao LV, Rapaport SI. Functional and binding studies of the roles of prothrombin and beta 2-glycoprotein I in the expression of lupus anticoagulant activity. Blood. 1994;83(10):2878-92.

56. Petri M, et al. Plasma homocysteine as a risk factor for atherothrombotic events in systemic lupus erythematosus. The Lancet. 1996;348:1120-4.

57. Obermoser G, Bitterlich W, Kunz F, Sepp NT. Thromboembolic risk in patients with high titre anticardiolipin and multiple antiphospholipid antibodies. Thromb Haemost. 2003;90:108-15.

58. Royal College of Obstetricians and Gynaecologists. Thromboprophylaxis during pregnancy, labour and after vaginal delivery. Guideline 2004; http://www. blackwellpublishing.com/medicine/bmj/nnf5/pdfs/ uk guidelines/ ENOXAPARIN.

59. Allahbadia GN, Allahadia SG. Low molecular weight heparin in immunological recurrent abortion- the incredible cure. J Assist Reprod Genet. 2005;20:82-90.

60. Park AL. Placental pathology in antiphospholipid syndrome. In: Khamashta MA, editor. Hughes' Syndrome. London: Springer-Verlag; 2006. p. $362-74$.

61. Kolyada A, et al. A novel dimeric inhibitor targeting Beta2GPI in Beta2GPI/antibody complexes implicated in antiphospholipid syndrome. PLoS One. 2010;5(12):e15345.

62. Broussas $M$, et al. Adenosine inhibits tissue factor expression by LPS-stimulated human monocytes: involvement of the A3 adenosine receptor. ThrombHaemost. 2002;88:123-30.
63. Mehdi AA, Uthman I, Khamashta M. Antiphospholipid syndrome: pathogenesis and a window of treatment opportunities in the future. Eur J Clin Invest. 2010;40(5):451-64. https://doi.org/10.1111/j.1365-2362.2010.02281.x. Epub 2010 Mar 25. PMID: 20345380.

64. Frank MB, McArthur R, Harley JB, Fujisaku A. Anti-Ro(SSA) autoantibodies are associated with $\mathrm{T}$ cell receptor beta genes in systemic lupus erythematosus patients. J Clin Invest. 1990;85(1):33-9. https://doi.org/10.1172/JCI114430. PMID: 1967259; PMCID: PMC296383.

65. Lee LA, et al. The autoantibodies of neonatal lupus erythematosus. J Invest Dermatol. 1994;102:963-6. (1996). The recognition of human 60-kDa Ro ribonucleoprotein particles by antibodies associated with cutaneous lupus and neonatal lupus. J Invest Dermatol, 107:225-228.

66. Bennion SD, Ferris, et al. IgG subclasses in the serum and skin in subacute cutaneous lupus erythematosus and neonatal lupus erythematosus. J Invest Dermatol. 1990;95:643-6.

67. Jaeggi E, et al. Evaluation of the risk of anti-SSA/ Ro-SSB/La antibody-associated cardiac manifestations of neonatal lupus in fetuses of mothers exposed to hydroxychloroquine. Ann Rheum Dis. 2010;69:1827.

68. Sonesson SE, Salomonsson, et al. Signs of firstdegree heart block occur in one-third of fetuses of pregnant women with anti-SSA/Ro 52-kd antibodies. Arthritis Rheu. 2004;50:1253.

69. Gordon PA. Congenital heart block: Clinical features and therapeutic approaches. Lupus. 2007;16:642-6.

70. Saleeb S, Copel J, Friedman D, et al. Comparison of treatment with fluorinated glucocorticoids to the natural history of autoantibody-associated congenital heart block. Arthritis Rheum. 1999;42:2335.

71. Yamada H, Kato EH, Ebina Y, et al. Fetal treatment of congenital heart block ascribed to anti-SSA antibody: case reports with observation of cardiohemodynamics and review of the literature. Am J ReprodImmunol. 1999;42:226.

72. Lawrence S, Luy, et al. The health of mothers of children with cutaneous neonatal lupus erythematosus differs from that of mothers of children with congenital heart block. Am J Med. 2000;108:705.9.

73. Lee LA, et al. Cutaneous Lupus erythematosus during the neonatal and childhood periods. Lupus. 1997;6:132-8.

74. Ostensen M, Villiger PM. The remission of RA during pregnancy semin. Immunopathol. 2007;29(2):185-91.

75. Doria A, Iaccarino L, Arieri $\mathrm{S}$, et al. $\mathrm{Th}_{2}$ Immune deviation induced by pregnancy: the two faces of auto immune rheumatic diseases. Reprod toxicol. 2006;22(2):234-41.

76. Forger F, Osensen M. is IgG galactosylation the relevant function for pregnancy- induced remission of Rheumatoid Arthritis? Arthritis Res Ther. 2010;12(1): 108 . 
77. Ostensen M. Glucocorticosteroids in Pregnant Patients with Rheumatoid Arthritis. Z Rheumato. 2000;59(8):1170-1174; PII 70 - II 74.

78. Hazer MW, var Heide H. Association of the higher Rheumatoid Arthritis Disease Activity During Pregnancy with Lower Birth Weight: Results of a national prospective study. Arthritis \& Rheumatism. 2009;60(11):3196-206.

79. Mecacci F, Pieralli B. The impact of Autoimmune Disorders and Adverse Pregnancy Outcome. 2007;31(4):223-6.

80. Amin S, Makol A. Rheumatoid Arthritis and Pregnancy: Safety Consideration in Pharmacological Management. Drugs. 2011;71(15):1973-87.

81. Sera DC, Siliva C. The Impact of Primary Sjogren's Syndrome on Pregnancy outcome: Our Series and Review of the Literature. Auto Immunity Reviews. 2014;13(2):103-7.

82. Sarwen Z, Hussein L, Jacobsson TH. Pregnancy and et fetal outcome in Women with Primary Sjogren's Syndrome compared with Women in the General Population: a Nested case-control study. Rheumatology. 2011;50(9):1612-7.

83. Ostensen M, Brucato A. Pregnancy and Reproduction in Autoimmune Rheumatic Disease. Rheumatology. 2011;50:657-64.

84. Sampaio-Barros PD, Samara AM. Gynaecologic History in Systemic Sclerosis. Clinical Rheumatology. 2000;19:184-7.

85. Minitati SG. Pregnancy in Systemic Sclerosis. Rheumto 2008; 47: iiii 16-iiii18.Monika Ostensen, Antonia Brucato. Pregnancy and Reproduction in Auto-immune Rheumatic Diseases. Rheumatology. 2011;50:657-64.

86. Gayed M, Gordon C. Pregnancy and Rheumatic Diseases. Rheumatology. 2007;46:1634-40.

87. Chakravarty EF, Culer V. Complications of systemic Sclerosis during Pregnancy. Int. J. Rheumatology. 2010:248-87.

88. Mitchell K, Kaul M. The management of Rheumatic Disease in Pregnancy. Scand J Rheumatol. 2010;39(2):99-108.

89. Qattoluca M, Mariagraziacanova L, et al. Pregnancy and vasculitis: A systemic Review of the Literature. Auto Immunity Reviews. 2012;11(6-7):447-59.
90. Doria GB. Prepregnancy Counselling of Patient's with Vasculitis. Rheumatology. 2008;47:iii13-5.

91. Wechsler JN. Behcet's Disease and Pregnancy. Arthritis and Rheumatism. 2013;65(9):2450-6.

92. Long Ford CA, Kerr GS. Pregnancy in Vasculitis. Current Opinion in Rheumatology. 2002;14(1):36-41.

93. Chang C. Neonatal auto-immune diseases: A Critical Review. Journal of Autoimmunity. 2012;38:J. 223-J238.

94. Cardy CM, Carruthers D. Large Vessel Vascultides. Medicine. 2010;38(2):97. -1-00

95. Philipseo MD. MHS Pregnancy and Vasculitis. Rheum Dis Clinic NAm. 2007;33:299-317.

96. Lang Ford CA, Gails K. Pregnancy in Vasculitis Current Opinion in Rheumatology. 2002;14(1):36-41.

97. Doria LA. Pregnancy in Rare Autoimmune rheumatic Disease; UCTD, MCTD, Myositis, Systemic Vasculitis and Bechet Diseases, Lupus. 2004;139(9):690-5.

98. Silva CA, Sulan SM. Pregnancy outcome in adultonset idiopathic inflammatory myopathy. Rheum. 2003;24:1168-72.

99. Gunuson L, Karaman S. Anesthetic Management for Cesarean Delivery in a Pregnant Woman with Poly myositis. A case report and review of literature. Cases J. 2009;2:9107.

100. Zhou Q, Bian X-m. Management of Pregnancy with Ankylosing Spondylitis. Chin Med Scij. 2012;27(1):46-9.

101. Bourlier RA, Birnbach DJ. Anesthetic Management of the Parturient with Ankylosing Spondylitis. International Journal of Obstetric Anesthesia. 1995;4:244-7.

102. Wetzl RG. Anesthesiological Aspects of Pregnancy in Patients with Rheumatic Disease. Lupus. 2004;13:699-702.

103. Al-Osaimi H, Yelamanchili SR. NLE \& SLE in Pregnancy, Text Book on Systemic Lupus Erythematosus, 1ST Edition Mar 2012, (21-23), P454-530. ISBN: 978-953-51-0266-3; www.intechopen.com.

Open Access This chapter is licensed under the terms of the Creative Commons Attribution 4.0 International License (http://creativecommons.org/licenses/by/4.0/), which permits use, sharing, adaptation, distribution and reproduction in any medium or format, as long as you give appropriate credit to the original author(s) and the source, provide a link to the Creative Commons license and indicate if changes were made.

The images or other third party material in this chapter are included in the chapter's Creative Commons license, unless indicated otherwise in a credit line to the material. If material is not included in the chapter's Creative Commons license and your intended use is not permitted by statutory regulation or exceeds the permitted use, you will need to obtain permission directly from the copyright holder. 